\title{
MANIFESTAÇÕES PATOLÓGICAS: FATORES QUE INFLUENCIAM NO SEU APARECIMENTO EM PRÉDIOS RESIDENCIAIS
}

\author{
RODRIGUES, ESAÚ DANIEL COSTAS \\ Graduando de Engenharia Civil \\ UNIFACEMA \\ Maranhão; Brasil \\ esau.rodrigues@outlook.com
}

\author{
SANTOS, MIKHAEL FERREIRA DA SILVA \\ Mestrando em Engenharia Civil \\ UFPE \\ Maranhão; Brasil \\ mikhael@ferreiraeng.com
}

\author{
FERREIRA, CLÁUDIO VIDRIH \\ Professor Doutor em Engenharia Civil \\ UNIFACEMA \\ Maranhão; Brasil \\ vidrih@vidrih.com.br
}

\author{
SANTOS, PAULO RICARDO ALVES REIS \\ Mestrando Engenharia de Materiais \\ IFPI \\ Maranhão; Brasil \\ pauloricardo.ars@gmail.com
}

\section{RESUMO}

Desde o estopim da civilização humana, o homem tem se preocupado em construir estruturas adaptadas às suas necessidades individuais e coletivas, sejam elas habitacionais, laborais ou de infraestrutura. O desenvolvimento tecnológico na construção civil se deu justamente através dessas necessidades, abrangendo concepção, projeto e execução. Apesar disso, diversas estruturas estão apresentando desempenho insatisfatório. Diante desse cenário, o presente trabalho apresenta o objetivo de avaliar os principais fatores que influenciam no aparecimento de manifestações patológicas em prédios residenciais no município de Caxias, estado do Maranhão. Para isso, foi catalogado grupos construtivos nas edificações levando em consideração a incidência dos principais problemas construtivos na região: instalações hidráulicas, alvenaria, impermeabilização, pisos e forro de gesso. Foram realizadas inspeções prediais, diagnóstico, prognóstico e terapia, seguindo os normativos brasileiro, tendo como a base a NBR 15575/2013, também conhecida como norma de desempenho. As manifestações patológicas encontratadas, por muitas vezes, não são tratadas com a devida solução, principalmente devido a falta de conhecimento dos usuários. Além das soluções indicadas, foi possível conscientizar a importância de profissionais capacitados, evitando problemas de concepção, projeto, execução ou pósocupação. Dentre os principais problemas encontrados, destaca-se ruptura em tubulações hidráulicas, acúmulo de ar nas tubulações, trincas, fissuras horizontais devido a variação térmica, fissuras verticais em paredes devido retração, fissuras por falta de verga e contraverga, problemas de umidade, entre outros.

Palavras-chave: patologia, manifestações patológicas, inspeção predial, desempenho, vida útil.

\section{ABSTRACT}

Since the beginning of human civilization, man has been involved in constructions built to suit his individual and collective needs, whether housing, laboratories or infrastructure. Technological development in civil construction took place only through these requirements, encompassing design, design and execution. Nevertheless, several structures are exhibiting unsatisfactory performance. Given this scenario, the present study aims to evaluate the main factors that influence the occurrence of pathological manifestations residential buildings in the city of Caxias, Maranhão state. For this, construction groups were cataloged in editions that take into consideration the main constructive problems in the region: hydraulic installations, masonry, waterproofing, floors and plasterboard. Pre-defined inspections, diagnosis, prognosis and therapy were performed following the Brazilian regulations, based on NBR 15575/2013, also known as the performance standard. As pathological manifestations found, they are often not treated with a proper solution, mainly due to lack of knowledge of users. In addition to the indicated solutions, it was possible to raise awareness of the importance of trained professionals, avoid problems of creation, design, execution or post occupation. Among the main problems encountered are the rupture of hydraulic lines, air drop in the pipes, cracks, horizontal cracks due to thermal variation, vertical wall cracks due to shrinkage, cracks due to lack of bending and counterbending, classification problems, among others.

Keywords: pathology, pathological manifestations, building inspection, performance, useful life. 


\section{INTRODUÇÃO}

A palavra patologia tem origem grega, onde pathos significa doença; e logos, estudo. Entretanto, patologia é igualmente usada na ciência como sinônimo de doença, o objetivo de seu estudo varia de acordo com o ramo de atividade (FACHIN; RIVELINE, 2016).

Na construção civil, define-se patologias como falhas ou manifestações patológicas que aparecem graças a inúmeros fatores, como mão de obra não especializada, matérias-primas de má qualidade, mau uso por parte dos proprietários e entre outros, podendo se manifestar em maior proporção na fase de uso da edificação.(FACHIN; RIVELINE, 2016). Ao tratar desse assunto, escuta-se repetidas vezes a palavra patologia e manifestações patológicas, porém, há um grande equívoco, tanto entre leigos e no meio técnico do uso apropriado da palavra, chama-se de patologia o que são manifestações patológicas e manifestações patológicas o que seria patologia. Diante disso, define-se manifestação patológica como a expressão resultante de um mecanismo de degradação e a patologia como a ciência formada por um conjunto de teorias que serve para explicar a causa da ocorrência de determinada manifestação patológica (FRANÇA et al., 2011).

Na engenharia as patologias têm que ser tratadas como algo sério. Segundo França (2011), a morte da estrutura pode ser comparada com à sua ruína. Dependendo do tipo e porte da edificação, a ruína pode ocasionar perdas de centenas de vidas, além de perdas financeiras.

Nos anos de 2015 e 2016 o Brasil teve um decréscimo de 3,8\% e 3,6\% respectivamente no produto interno bruto (PIB), e $1 \%$ positivo em 2017. A construção civil, é uma das mais afetadas. Segundo a Câmara Brasileira da Indústria da Construção Civil (Cbic), o PIB da construção civil acumula queda desde 2014, quando foi observada a primeira redução, de 2,1\%. Essa queda permaneceu acontecendo em 2015 (-9,0\%), 2016 (-5,6\%) e 2017 (-5,0\%). Alguns dados de 2018 começam a ser divulgados e mostram a persistente lentidão na retomada do setor, com a queda de $0,6 \%$ no primeiro trimestre do ano. Já o PIB brasileiro dos primeiros três meses de 2018 apresentou um tímido crescimento, de apenas 0,4\% (FERREIRA, 2018).

Para as empresas e/ou profissionais se adequarem ao mercado competitivo, estão produzindo produtos de menor preço, economizando em materiais ou em mão de obra e se esquecendo de prezar por um fator muito importante, a qualidade. Com o aparecimento das manifestações patológicas, surge uma necessidade de contratar uma mão de obra de reparo que por sua vez se torna mais cara que a mão de obra de implantação, gerando custos adicionais e incômodo ao consumidor, nascendo um produto "barato", porém caro.

Diante disso, esse trabalho tem como objetivo expor as manifestações patológicas mais recorrentes em prédios residencias no município de Caxias, estado do Maranhão, elencando suas causas, prevenção e manutenção, gerando conhecimento para pessoas leigas ou profissionais de como devem ser feitas as reduções de custos e onde não podem economizar, considerando suas consequências.

Manifestações patológicas é um assunto que dentro da construção civil tem ganhado bastante espaço devido ao seu grande aparecimento nas últimas décadas, no Brasil, as edificações têm apresentado o aparecimento de manifestações patológicas precoces que são decorrentes de vários fatores e um dos principais seria a redução de custos. Essa economia não é errada, porém as pessoas não estão sabendo administrar e nem sabendo até onde ir nessa variável (BENTO et al., 2016).

Buscando reparar esse déficit a Associação Brasileira de Normas Técnicas publicou em 2013 a NBR 15575, que tem como objetivo melhorar a qualidade das edificações para atender as exigências do consumidor final, atrelando o conceito de desempenho de durabilidade e vida útil dos diversos sistemas da edificação.

\section{MATERIAIS E METODOS}

\subsection{Tipo de estudo}

O presente estudo consistiu em uma pesquisa com objetivo descritivo comparativo no qual foram analisadas manifestações patológicas recorrentes em prédios residenciais no município de Caxias, estado do Maranhão. 
O cenário de estudo constitui técnicas de pesquisa através de documentação indireta abrangendo a pesquisa bibliográfica e documental. Além do estudo de caso que consistiu no levantamento de dados referentes a manifestações patológicas em casas residenciais.

\subsection{Revisão bibliográfica}

A revisão abrange bibliografias já tornada pública em relação ao tema de estudo, desde publicações avulsas, boletins, jornais, revistas, livros, pesquisas, monografias, teses, material cartográfico, etc., tendo como finalidade colocar o pesquisador em contato direto com tudo o que será escrito (MARCONI; LAKATOS, 2003).

Foi a fase da pesquisa realizada com intuito de recolher informações prévias sobre manifestações patológicas em obras residenciais, suas causas, além dos procedimentos mais adequados para a sua execução, assim como, utilizar-se disso para realizar comparações, com os dados que serão aferidos no estudo de caso.

\subsection{Estudo de caso}

Consistiu na coleta de dados em casas residenciais. Os estudos foram baseados em manifestações patológicas encontradas nas edificações visitadas de maneira a realizar um comparativo das manifestações existentes com as aferidas a partir da revisão bibliográfica, elencando suas causas, prevenção e manutenção das manifestações que serão citadas.

É importante salientar que as coletas foram extraídas em diferentes períodos do calendário de maneira que o resultado fosse obtido no prazo estipulado.

\subsection{Elaboração dos resultados}

A partir do comparativo entre a revisão e os dados coletados, foi realizado uma avaliação das manifestações patológicas existentes e suas possíveis causas, em seguida, buscou-se informações sobre as formas mais adequadas para manutenção e correções da patologia.

Portanto, foi possível conhecer os problemas já debatidos e explicar como a escolha do material e da mão de obra influenciará na qualidade e custo da construção. Além de explorar novas áreas e perspectivas que poderão ser abordadas.

\section{RESULTADOS E DISCUSSÃO}

Alinhados os resultados obtidos na pesquisa de campo e bibliográfico foi possível detalhar cada manifestação obedecendo os grupos previamente escolhidos: 1- Instalações hidráulicas; 2- Alvenaria; 3- Impermeabilização; 4- Pisos; 5- Forro de gesso.

\subsection{Instalações hidráulicas}

Segundo Vieira (2016), 75\% das patologias da construção são decorrentes de problemas relacionados com as instalações hidráulicas prediais. Isso é uma demonstração de que os sistemas hidráulicos prediais não estão merecendo a atenção necessária e indispensável para que tenham o seu desempenho de acordo com a vida útil da edificação. Essa condição é decorrente de algumas evidências, tais como:

a) Instalações hidráulicas e sanitárias estão ocultas;

b) Execução de obras sem os projetos de instalações;

c) Preocupação em reduzir custos nas instalações;

d) Aplicações de componentes / materiais de baixa qualidade;

e) Baixa qualificação na mão de obra utilizada;

Neste trabalho será abordar três tipos dos quais tiveram mais ocorrências, são eles: 1) Rupturas em engates flexíveis; 2) Acúmulo de ar na tubulação; 3) Trincas em conexões. 


\subsubsection{Rupturas em engates flexíveis}

Os engates flexíveis são destinados a fazer a ligação de materiais sanitários ao ponto de fornecimento de agua. As rupturas em engastes flexíveis foram encontradas na coleta realizada.

Há disponível no mercado brasileiro engates flexíveis fabricados em material plástico ou material metálico, conforme mostra a Figura 01. A diferença entre um e outro, além do material de fabricação, é a capacidade de suportar pressões e temperaturas. As rupturas desse material ocorrem normalmente no corpo do flexível ou nas porcas de engates plásticos, as quais eventualmente são submetidas ao excesso de aperto, procedimento que vai contra ao que recomenda o fabricante. A Figura 02 mostra o engate plástico contendo ruptura por excesso de aperto com o uso de ferramenta tipo chave de grifo, fato ocorrido em uma das casas visitadas.

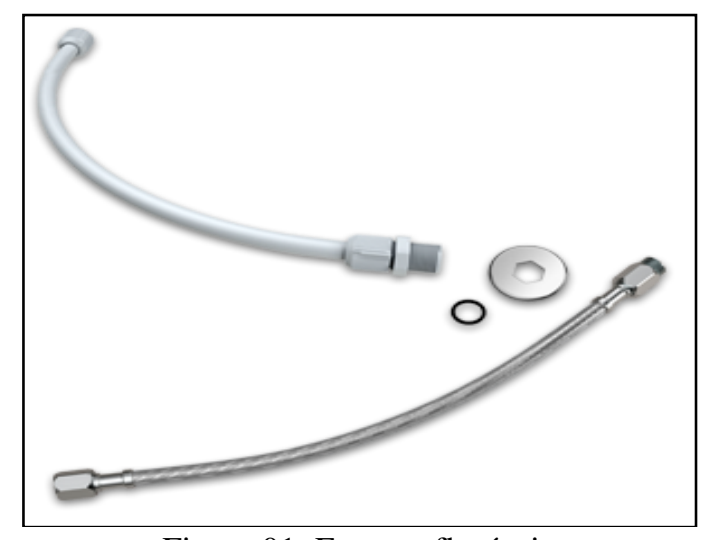

Figura 01: Engates flexíveis

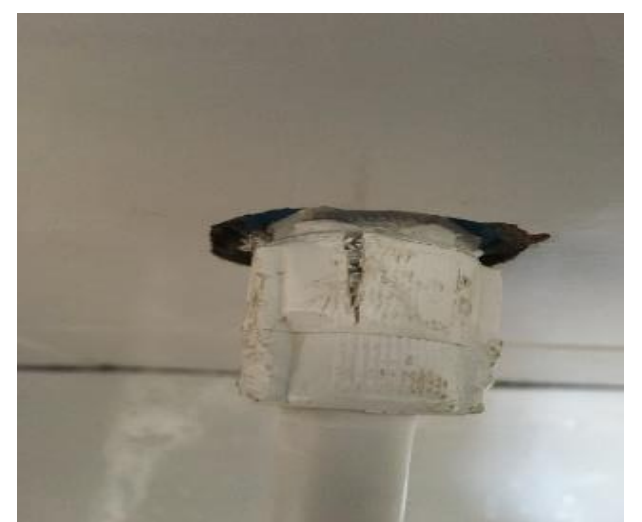

Figura 02: Engates flexíveis - ruptura na porca

As medidas de correção sugeridas são: 1- Utilização de engates metálicos, pois proporcionará maior resistência ao aperto; 2- Se for utilizar engates plásticos deve-se atentar ao manual de utilização do material, para não ocorrer a má utilização e nem uma montagem incorreta do mesmo.

\subsubsection{Acúmulo de ar na tubulação}

A formação de bolsões de ar na canalização de água fria foi observada em três residências visitadas, o acontecimento dessa anomalia ocorre com frequência, ocasionando a falta de água.

A falta de água decorrente do esvaziamento do reservatório, voluntariamente ou não, é um fator que gera a possibilidade de formação de bolsas de ar na tubulação e a consequente obstrução da passagem da água para os pontos de consumo diversos. Se há formação de bolsas de ar nas tubulações de água, é um indicativo de que os tubos ventiladores não estão cumprindo a finalidade para a qual se destinam, ou seja, expulsar as bolhas de ar presas nos barriletes, fato que ocorre sempre que o reservatório superior fica esvaziado e volta a ser cheio.

Esse fato ocorre principalmente por erros na execução da montagem dos tubos ventiladores do reservatório de agua.

\subsubsection{Trincas em conexões}

As tubulações estão sujeitas às trincas por causas diversas. Entre elas, o tensionamento sendo considerado um grande fator que leva ao colapso de uma tubulação, pois trata-se de um esforço mecânico externo que força a conexão por desalinhamento na tubulação, golpe de aríete, vibrações transmitidas por equipamentos (moto bombas, etc.), dilatação e contração térmica da tubulação e até o recalque em terrenos (VIEIRA, 2016).

Trincas em conexões hidráulicas são sinistros que podem causar danos materiais de grande proporção, foi utilizado como exemplo um caso vivenciado na pesquisa: uma casa com apenas 3 meses de uso, a trinca ocorreu no joelho que faz conexão da água proveniente da caixa d'água com a alimentação para à casa (figura 03) da qual se localiza na cobertura entre o quarto e banheiro, esse acontecimento danificou parte dos móveis, acabamento em pintura, placas de gesso, fora o incomodo que trousse aos moradores como mostra a figura 04 e figura 05. 


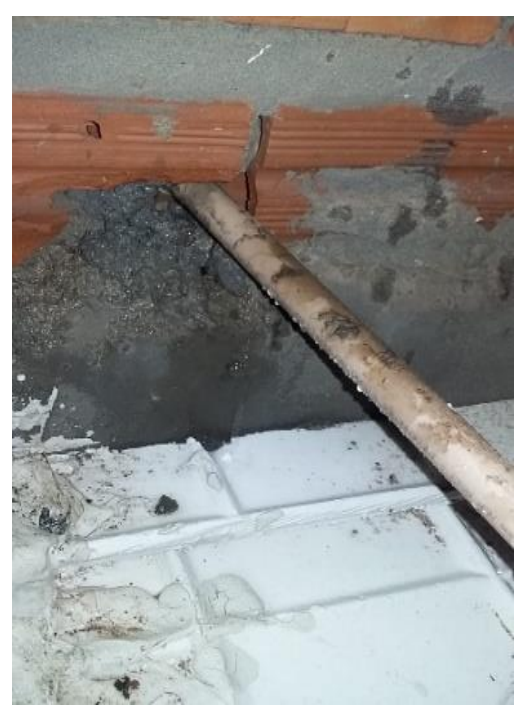

Figura 03: Trinca no Joelho

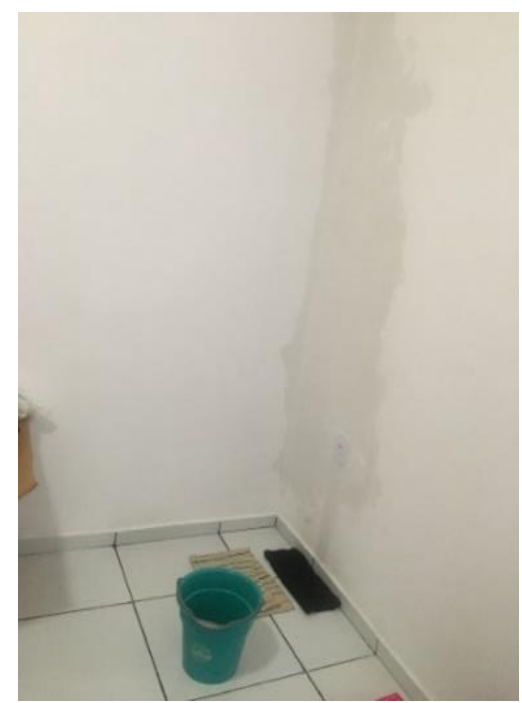

Figura 04: Revestimento em pintura danificado

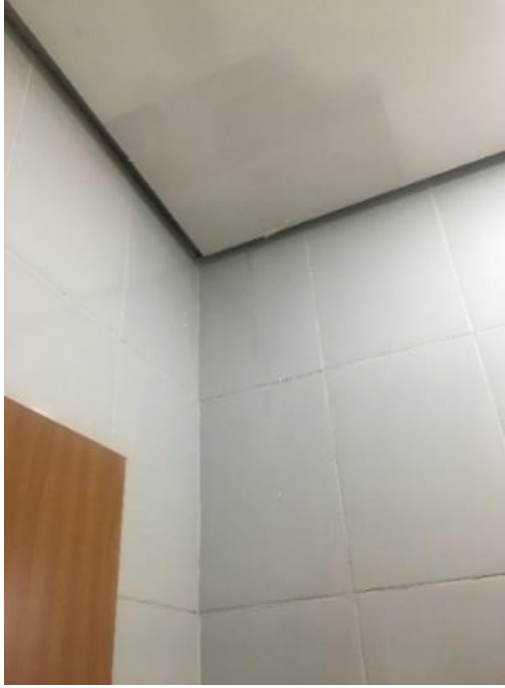

Figura 05: Placas de gesso danificadas

Nesse caso especifico, foi detectado o agente que ocasionou esse sinistro, a economia que a construtora fez na escolha do material; constatou-se que a mesma adquiriu materiais de péssima qualidade e ressecados na intenção de obter economia no orçamento final. A tubulação foi bem dimensionada e bem executada porem a má escolha do material ocasionou no surgimento dessa manifestação.

\subsection{Alvenarias}

Segundo Lima (2015), várias são as patologias que podem ser encontradas em alvenarias, como fissuras, desnivelamento de superfícies, entre outros. No entanto, a manifestação patológica que se dá ênfase é a fissura, devido a aspectos fundamentais, como o comprometimento da obra em serviço (estanqueidade à água, isolamento térmico e acústico, durabilidade, etc.), o constrangimento e preocupação psicológicos que a fissuração do edifício exerce sobre seus usuários devido a um eventual estado de perigo para a estrutura, etc.

Os principais mecanismos de formação das fissuras, são: - Movimentações provocadas por variações térmicas e de umidade; - Atuação de sobrecargas ou concentração de tensões; - Deformabilidade excessiva das estruturas; - Retração de produtos à base de ligantes hidráulicos.

As manifestações patológicas em alvenarias ainda são bem frequentes no Brasil, devido à comunicação precária entre seus envolvidos, como engenheiros que executam a obra, projetistas e os fabricantes de materiais e componentes da construção. Essa pode ser a principal razão do surgimento dessas com tanta frequência.

As fissuras em paredes podem ser classificadas com critérios diferentes, como as causas, o tipo a atividade, a abertura, a forma, a direção, as tensões envolvidas, entre outras. Frequentemente, a configuração típica, a dimensão e a magnitude de uma fissura permite que se especule sua causa provável. As figuras 06 a 09, apresentam os quadros resumo das 25 configurações típicas catalogadas, reunidas em seus respectivos grupos (MAGALHÃES, 2004)

A partir desses catálogos foi possível identificar os tipos de fissuras encontradas na pesquisa de campo e identificar causas prováveis além de elencar possíveis medidas de terapia e prevenção. 


\begin{tabular}{|c|c|l|l|}
\hline 3.1 & SOBRECARGAS & Fissuras causadas por sobrecargas \\
\hline 3.1 .1 & & $\begin{array}{l}\text { Fissuras verticais induzidas por } \\
\text { sobrecargas }\end{array}$ \\
\hline 3.1 .2 & & Fissuras horizontais por sobrecargas \\
\hline 3.1 .3 & & \\
\hline 3.1 .4 & & \\
\hline 3.1 .5 & & \\
\hline
\end{tabular}

Figura 06: Configurações típicas de fissuras

\begin{tabular}{|c|c|c|}
\hline 3.2 & TÉRMICAS & $\begin{array}{l}\text { Fissuras causadas por variações de } \\
\text { temperatura }\end{array}$ \\
\hline 3.2 .1 & 虏 & $\begin{array}{l}\text { Fissuras horizontais por movimentação } \\
\text { témica da laje }\end{array}$ \\
\hline 3.2 .2 & & $\begin{array}{l}\text { Fissuras inclinadas por movimentação } \\
\text { témica da laje }\end{array}$ \\
\hline 3.2 .3 & & $\begin{array}{l}\text { Fissuras inclinadas em paredes } \\
\text { transversais por movimentação térmica da } \\
\text { laje }\end{array}$ \\
\hline 3.2 .4 & E & $\begin{array}{l}\text { Fissuras verticais por movimentação } \\
\text { témica da laje }\end{array}$ \\
\hline 3.2 .5 & & $\begin{array}{l}\text { Fissuras inclinadas por movimentação } \\
\text { témica da estrutura de concreto armado }\end{array}$ \\
\hline 3.2 .6 & = & $\begin{array}{l}\text { Fissuras de destacamento por } \\
\text { movimentação térmica da estrutura de } \\
\text { concreto armado }\end{array}$ \\
\hline 3.2 .7 & & $\begin{array}{l}\text { Fissuras verticais por movimentação } \\
\text { témica da alvenaria }\end{array}$ \\
\hline 3.2 .8 & & $\begin{array}{l}\text { Fissuras de destacamento de platibandas } \\
\text { por movimentação térmica }\end{array}$ \\
\hline
\end{tabular}

Figura 07: Configurações típicas de fissuras

\begin{tabular}{|c|c|c|}
\hline 3.4 & DEFORMAÇÖES & $\begin{array}{l}\text { Fissuras causadas por deformação de } \\
\text { elementos da estrutura de concreto } \\
\text { armado }\end{array}$ \\
\hline 3.4 .1 & $\overbrace{5}^{2}$ & $\begin{array}{l}\text { Fissuras em paredes por deformação do } \\
\text { apoio }\end{array}$ \\
\hline 3.4 .2 & & $\begin{array}{l}\text { Fissuras em paredes por deformação das } \\
\text { vigas de apoio e superior }\end{array}$ \\
\hline 3.4.3 & L & $\begin{array}{l}\text { Fissuras em paredes por deformação da } \\
\text { viga superior }\end{array}$ \\
\hline 3.4.4 & & $\begin{array}{l}\text { Fissuras em paredes com aberturas por } \\
\text { deformação da estrutura }\end{array}$ \\
\hline 3.4 .5 & & $\begin{array}{l}\text { Fissuras em paredes por deformação de } \\
\text { balanços }\end{array}$ \\
\hline 3.4 .6 & & $\begin{array}{l}\text { Fissuras horizontais em paredes por } \\
\text { deformação da laje de cobertura }\end{array}$ \\
\hline
\end{tabular}

Figura 08: Configurações típicas de fissuras

\begin{tabular}{|c|c|c|}
\hline 3.3 & $\begin{array}{l}\text { RETRAÇÃO- } \\
\text { EXPANSÃO }\end{array}$ & $\begin{array}{l}\text { Fissuras causadas por retração e } \\
\text { expansão }\end{array}$ \\
\hline 3.3.1 & $\bar{\square}$ & $\begin{array}{l}\text { Fissuras horizontais em paredes por } \\
\text { retração da laje }\end{array}$ \\
\hline 3.3.2 & 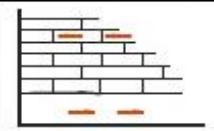 & $\begin{array}{l}\text { Fissuras na base de paredes por retração } \\
\text { da laje }\end{array}$ \\
\hline 3.3.3 & & $\begin{array}{l}\text { Fissuras verticais em paredes por retração } \\
\text { da laje }\end{array}$ \\
\hline 3.3.4 & 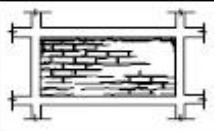 & $\begin{array}{l}\text { Fissuras de destacamento de paredes de } \\
\text { alvenaria por retração }\end{array}$ \\
\hline 3.3.5 & $\rightarrow \leftarrow \mid \rightarrow$ & $\begin{array}{l}\text { Fissuras verticais em paredes por retração } \\
\text { da alvenaria }\end{array}$ \\
\hline 3.3.6 & 者: & $\begin{array}{l}\text { Fissuras horizontais por expansão da } \\
\text { alvenaria }\end{array}$ \\
\hline 3.3.7 & & $\begin{array}{l}\text { Fissuras verticais por expansão da } \\
\text { alvenaria }\end{array}$ \\
\hline
\end{tabular}

Figura 09: Configurações típicas de fissuras

Através do comparativo entre catálogo citado anteriormente e a pesquisa de campo foi possível identificar os tipos de fissuras encontradas nas edificações visitadas, em duas residências foram detectadas fissuras causadas por variações de temperaturas, em outras duas fissuras causadas por retração e expansão, em outra fissura vertical induzida por sobrecargas. 3.2.1. Fissuras causadas por variações de temperaturas 
Os diversos elementos que compõem as construções estão expostos às variações de temperatura sazonais e diárias que provocam movimentos de dilatação e contração que, associados às diversas restrições existentes à sua movimentação, resultam em tensões que podem provocar fissuras de temperatura (MAGALHÃES, 2004).

As fissuras causadas por variações de temperatura ainda podem se dividir em 8 tipos distintas, sendo: 1 - Fissuras horizontais por movimentação térmica da laje; 2 - Fissuras inclinadas por movimentação térmica da laje; 3 - Fissuras inclinadas em paredes transversais por movimentação térmica da laje; 4 - Fissuras verticais por movimentação térmica da laje; 5 - Fissuras inclinadas por movimentação térmica da estrutura de concreto armado; 6 - Fissuras de destacamento por movimentação térmica da estrutura de concreto armado; 7 - Fissuras verticais por movimentação térmica da alvenaria; 8 - Fissuras de destacamento de platibandas por movimentação térmica. Na pesquisa realizada detectou-se um tipo de fissuras causadas por variações de temperatura, sendo ela bem fácil de ser encontrada em diversas edificações, as fissuras horizontais por movimentação térmica da laje.

- $\quad$ Fissuras horizontais por movimentação térmica da laje

As fissuras horizontais por movimentação térmica da laje ocorrem em paredes de alvenaria que sustentam lajes de concreto armado expostas às variações de temperatura, especialmente as lajes de cobertura. A forma destas fissuras é tipicamente horizontal, na interface entre a parede de alvenaria e a laje de concreto armado, ou mais abaixo, em uma linha paralela à laje. Coberturas rígidas, mesmo que não construídas em concreto armado, também podem provocar fissuras com esta mesma configuração (MAGALHÃES, 2004). As figuras 10 e 11 apresentam os casos encontrados dos quais apresentam as configurações típicas deste tipo de fissuração.

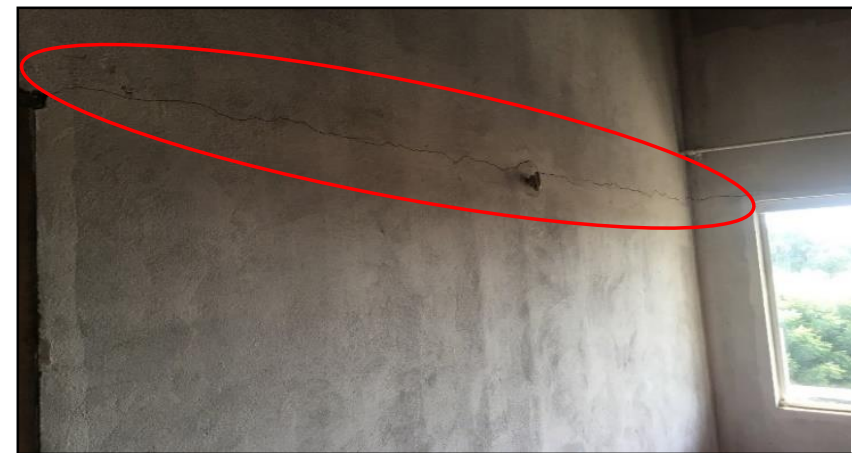

Figura 10: Fissuras horizontais por movimentação térmica da laje

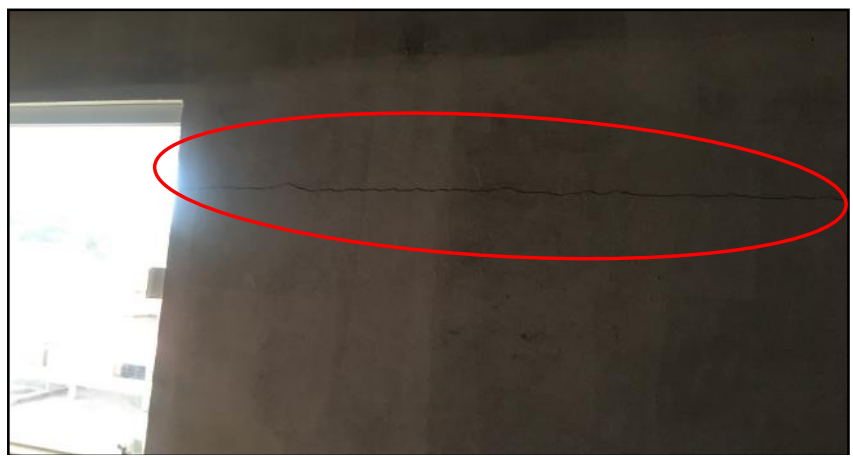

Figura 11: Fissuras horizontais por movimentação térmica da laje

\subsubsection{Fissuras causadas por retração}

Segundo Magalhães (2004) são manifestações ocasionadas pela movimentação de elementos construtivos ou de seus constituintes por retração de produtos à base de cimento. Podem ser provocadas em paredes de alvenaria de duas formas: pela retração dos materiais constituintes das alvenarias, ou ainda, pela movimentação por retração de outros elementos construtivos, como as lajes e vigas de concreto armado por exemplo, causando fissuras nas paredes de alvenaria adjacentes a estes elementos.

Esse tipo de fissura se divide em 5 tipos distintos, são eles: 1 - Fissuras horizontais em paredes por retração da laje; 2 Fissuras na base de paredes por retração da laje; 3 - Fissuras verticais em paredes por retração da laje; 4 - Fissuras de destacamento de paredes de alvenaria por retração; 5 - Fissuras verticais em paredes por retração da alvenaria. Na pesquisa foi identificado fissuras de destacamento de paredes de alvenaria por retração e fissuras verticais em paredes por retração da alvenaria.

- $\quad$ Fissuras de destacamento de paredes de alvenaria por retração

As fissuras de destacamento de paredes de alvenaria por retração como mostra a figura 12, são fissuras horizontais e verticais que ocorrem na interface entre a parede e a estrutura de concreto armado. A retração por secagem das argamassas de assentamento pode provocar o abatimento de paredes de alvenaria recém executadas, provocando o seu destacamento. Também a última fiada da alvenaria executada prematuramente poderá sofrer com este abatimento, provocando seu 
superior ou laje; A retração das argamassas de assentamento pode provocar ainda destacamentos localizados entre a argamassa e o componente da alvenaria, como tijolos ou blocos, gerando fissuras de pequeno porte na interface entre o componente e a argamassa (THOMAZ, 1989).

- $\quad$ Fissuras verticais em paredes por retração da alvenaria

Fissuras verticais em paredes podem ocorrer pela retração da própria alvenaria que, além do destacamento, pode induzir a formação de fissuras no próprio corpo da parede. Em geral ocorrem pela retração de seus elementos constituintes, como tijolos ou blocos e/ou juntas de argamassa (THOMAZ, 1989).

Fissuras verticais em paredes por retração da alvenaria (figura 13), podem apresentar variações, mantendo uma orientação predominantemente vertical (MAGALHÃES, 2004).

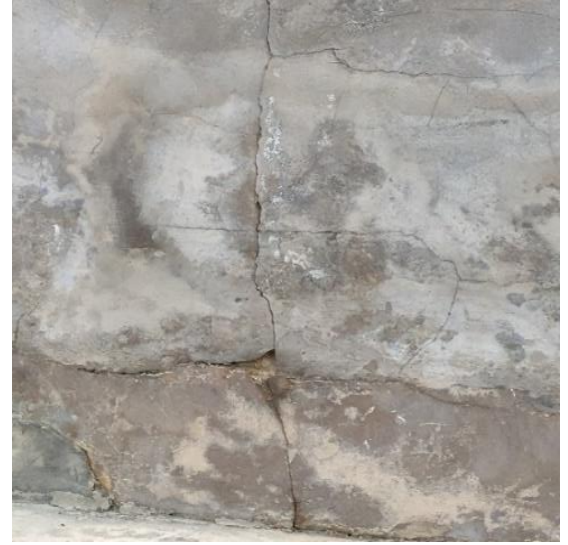

Figura 12: Fissuras de destacamento de paredes de alvenaria por retração

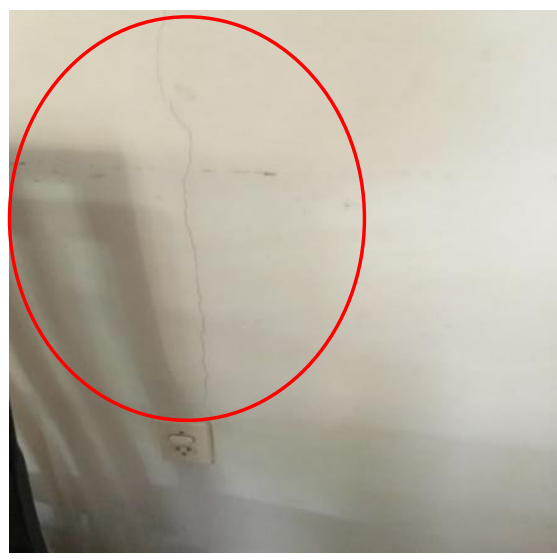

Figura 13: Fissuras verticais em paredes por retração da alvenaria

\subsubsection{Fissura induzida por sobrecarga}

Muitos são os fatores que influenciam na fissuração de paredes em alvenaria submetidas a sobrecargas de compressão: a forma, seção transversal e esbeltez; o tipo e forma geométrica dos tijolos ou blocos; a resistência mecânica e os módulos de deformação destes componentes e da junta de argamassa; a rugosidade e porosidade dos componentes; o poder de aderência, elasticidade, retração e retenção de água da argamassa; o tipo de junta de assentamento, sua espessura e regularidade; o tipo de fixação da parede a outras estruturas; e, as técnicas construtivas e qualidade de execução (MASSETO; SABBATINI, 1998)

Como em todos os tipos de fissuras, a fissura induzida por sobrecarga é dividida em 5 tipos, sendo eles: 1 - Fissuras verticais induzidas por sobrecargas; 2 - Fissuras horizontais por sobrecargas; 3 - Fissuras por sobrecargas em apoios; 4 Fissuras por sobrecargas em pilares de alvenaria; 5 - Fissuras por sobrecargas em torno de aberturas. Em nosso estudo identificou-se um dos tipos: fissuras por sobrecargas em torno de aberturas, esse tipo de fissura é fácil de ser encontrada em diversas edificações.

- $\quad$ Fissuras por sobrecargas em torno de aberturas

Ocorrem em paredes descontínuas, com aberturas submetidas a carregamentos de compressão excessivos e têm como característica a formação de fissuras a partir dos vértices das aberturas. Podem apresentar-se com diversas formas, em função de múltiplos fatores como dimensões da parede e das aberturas, materiais constituintes da parede, dimensão e rigidez de vergas e contravergas, deformação e comportamento da alvenaria e de seu suporte (THOMAZ, 1989).

Na maioria dos casos essas sobrecargas em torno das aberturas podem ser combatidas apenas com emprego de uma peça estrutural conhecida como verga (quando forem portas e janelas) e contravergas (quando for janelas ou basculantes). Na figura 14 e 15 pode-se observar o comportamento desse tipo de fissura. 


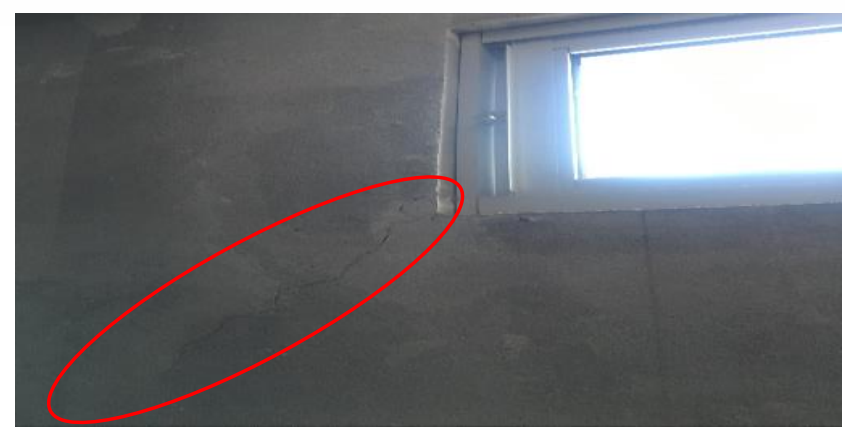

Figura 14: Fissura por sobrecargas em torno de abertura

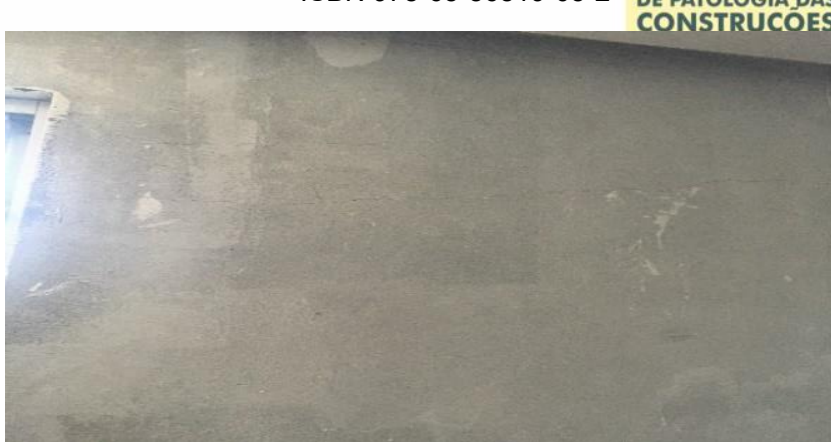

Figura 15: Fissura por sobrecargas em torno de abertura

\subsection{Impermeabilização}

Os problemas de umidade podem se manifestar em diversos elementos das edificações: paredes, pisos, fachadas, elementos de concreto armado, etc. Geralmente eles não estão relacionados a uma única causa. Quando surgem nas edificações, sempre trazem um grande desconforto e degradam a construção rapidamente (SOUZA, 2008).

De acordo com a NBR 9575 (ABNT, 2010), a impermeabilização é o conjunto de operações e técnicas construtivas (serviço), composto por uma ou mais camadas, que tem por finalidade proteger as construções contra ação deletéria de fluídos, de vapores e da umidade.

Para a execução dessa atividade faz-se necessário a existência de um projeto de impermeabilização, pois todos os cuidados serão poucos para que vazamentos não voltem a ocorrer, pois parte dos problemas com os sistemas ocorrem em encontros com ralos, juntas, mudança de planos, passagem de dutos e chubamentos (LIMA, 2015). A umidade é um dos problemas mais difíceis de ser resolvidos na construção civil.

Identificamos em uma das residências visitadas uma parede com umidade generalizada, como mostra a figura 16, foi-se possível identificar com facilidade a origem da patologia, os proprietários da edificação ainda indicaram que a patologia se manifestou após uma noite de chuva, também foi verificado que a mesma parede se encontra com tijolos a vista na parte externa. Souza (2008) cita, uma causa poderia ser o reboco poroso, outra o reboco salpicado, que é capaz de reter água, que irá atravessar a parede. Em se tratando de paredes de tijolo à vista, a causa de infiltração é devido às juntas malfeitas.

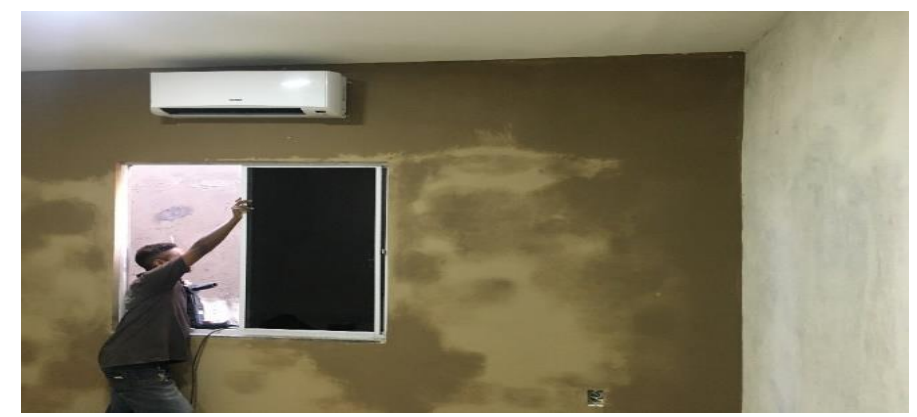

Figura 16: Umidade generalizada

\subsection{Pisos}

Segundo Rhod (2011) a maioria das ocorrências de manifestações patológicas em revestimento cerâmico pode ser atribuída à falta de compreensão das interfaces entre seus diversos componentes. Essa falta de compreensão está ligada às deficiências no conhecimento técnico de toda a cadeia produtiva, destacando: 1- Assentadores despreparados e sem treinamento; 2- Fabricantes não preocupados com garantia, assistência técnica e informações de uso; 3- Projetistas desconhecedores de suas responsabilidades; 4- Incorporadores não atentos ao real valor atribuído à relação entre custos de recuperação da manifestação patológica e o valor do bem a ser recuperado. 
Os principais tipos de patologias que ocorrem em revestimentos cerâmicos são: destacamentos de placas, trincas, manchas e deterioração de juntas; nessa pesquisa iremos destacar dois tipos considerados principais, são eles: Trincas e Deterioração de juntas.

\subsubsection{Trincas}

Este fenômeno caracteriza-se por perda de integridade da superfície do revestimento cerâmico, podendo até mesmo levar ao seu descolamento do substrato (BARROS; FLAIN; SABBATINI, 1993). A figura 17 caracteriza essa manifestação.

Segundo Rhod (2011) as principais causas para os problemas de trincas, são:

a) Dilatação e retração das placas cerâmicas: ocorre quando há variação de temperatura ou de umidade;

b) Deformação estrutural excessiva: a deformação da estrutura do edifício pode criar tensões que são transmitidas para a alvenaria e desta para os revestimentos.

c) retração da argamassa de fixação: ocorre principalmente quando a argamassa de fixação é dosada na obra, causando retração excessiva pela perda da água de amassamento, podendo tornar a superfície da placa convexa e tracionada.

\subsubsection{Deterioração de juntas}

Os rejuntes, em geral, não vem sendo considerados como um serviço técnico de importância para o desempenho do conjunto do revestimento. Na realidade, desconhece-se as suas verdadeiras funções, atribuindo-lhes somente à estética do conjunto (BARROS; FLAIN; SABBATINI, 1993).

A deterioração das juntas figura 18, apesar de afetar as argamassas de preenchimento das juntas de assentamento e de movimentação, compromete todo o revestimento cerâmico, interferindo na sua capacidade de absorver deformações.

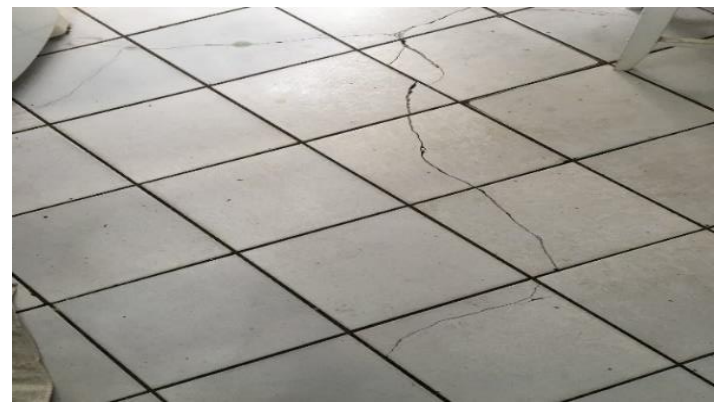

Figura 17: Trincas em revestimento cerâmico

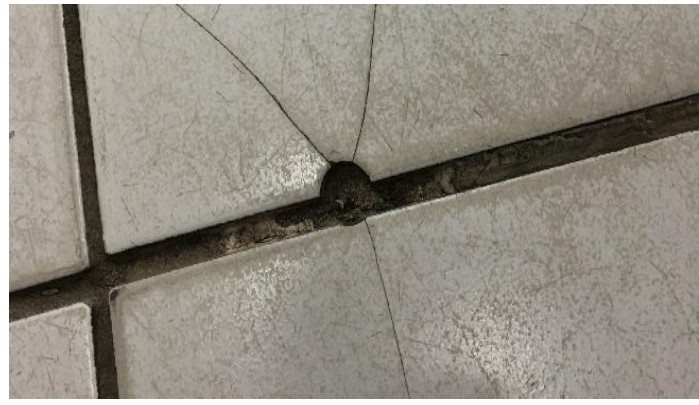

Figura 18: Deterioração de junta

Por isso, a escolha correta do material e o controle de execução do rejuntamento são as maneiras de se evitar essa manifestação patológica (LIMA, 2015). Existe duas formas dela se manifestar: pela perda de estanqueidade da junta ou pelo envelhecimento do material de preenchimento.

A perda de estanqueidade das juntas, muitas vezes, inicia-se logo após sua execução, pois procedimentos inadequados de limpeza, promovem a deterioração de parte de seu material constituinte que, somada aos ataques agressivos do meio ambiente, ou de solicitações devido a movimentos diferenciais, desencadeiam um estado de vulnerabilidade de sua integridade, podendo originar fissuras ou mesmo trincas ocorrendo, assim, o processo de desenvolvimento de um problema patológico como o descolamento e a eflorescência, por exemplo, pela possibilidade de infiltração de água (BARROS; FLAIN; SABBATINI, 1993).

\subsection{Forro de gesso}

Dentre as manifestações patológicas que ocorrem em casas residenciais, são comuns o surgimento em placas e revestimento de gesso, os defeitos mais comuns são trincas e fissuras (figura 19), causadas pela interação entre forro e acomodação da estrutura. 


\section{CBPAT 2020

Para evitar trincas em forros de gesso, é necessário que se permita a livre movimentação do gesso. Para tanto, recomenda que sejam feitas juntas de ligação, que são as que ficam localizadas entre o forro e as paredes ou elementos da estrutura, permitindo a movimentação diferencial. Independentemente das dimensões do forro, as juntas devem ser executadas em todo o perímetro entre o forro e as paredes ou divisórias, bem como entre o forro e os elementos da estrutura em contato com ele (LIMA, 2015).

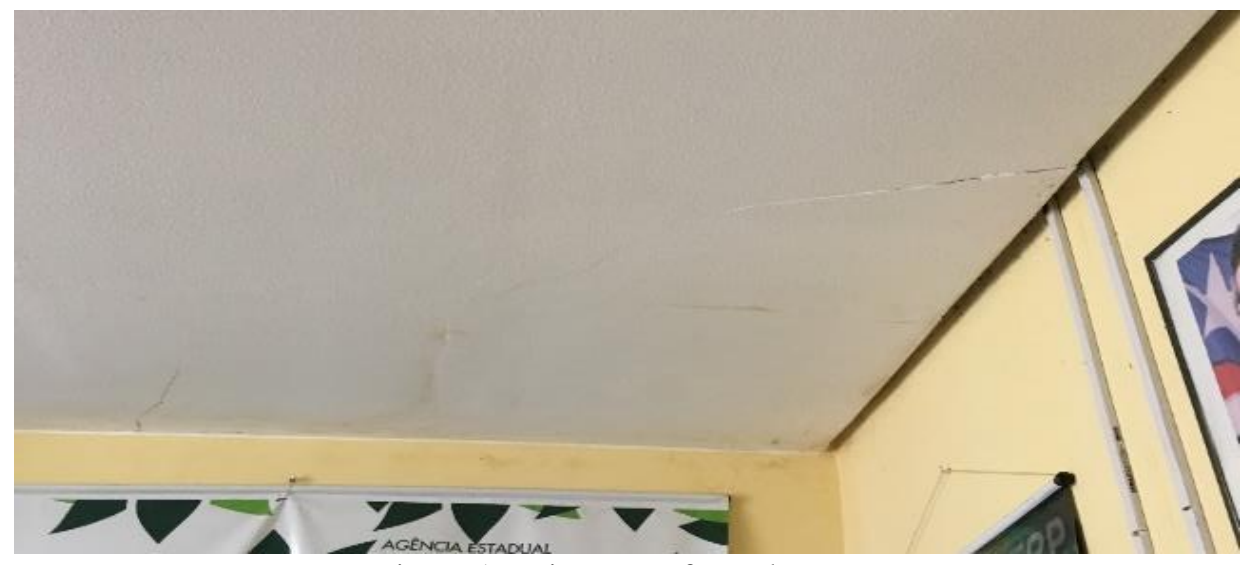

Figura 19: Fissura no forro de gesso

\subsection{Sintese das manifestações ocorrentes na pesquisa}

Neste trabalho, foram estudadas diversas casas residenciais em bairros e construtoras diferentes, no intuito de catalogar as manifestações patológicas mais ocorrentes em casas residenciais elencando suas causas, prevenção e manutenção. Para melhor entendimento a tabela 01 apresenta os tipos de manifestações patológicas registradas e analisadas no presente trabalho.

Tabela 01: Manifestações patológicas registradas

\begin{tabular}{|c|c|c|}
\hline \multicolumn{3}{|c|}{ MANIFESTAÇÕES OCORRENTES NA PESQUISA } \\
\hline GRUPO & SUBGRUPO & MANIFESTAÇÃO PATOLÓGICA \\
\hline \multirow{3}{*}{$\begin{array}{l}\text { INSTALAÇÕES } \\
\text { HIDRÁULICAS }\end{array}$} & & RUPTURAS EM ENGATES FLEXÍVEIS \\
\hline & & ACÚMULO DE AR NA TUBULAÇÃO \\
\hline & & TRINCAS EM CONEXÕES \\
\hline \multirow{4}{*}{ ALVENARIAS } & $\begin{array}{c}\text { FISSURAS CAUSADAS POR } \\
\text { VARIAÇÕES DE TEMPERATURAS } \\
\end{array}$ & $\begin{array}{c}\text { FISSURAS HORIZONTAIS POR } \\
\text { MOVIMENTAÇÃO TÉRMICA DA LAJE }\end{array}$ \\
\hline & \multirow{2}{*}{$\begin{array}{l}\text { FISSURAS CAUSADAS POR } \\
\text { RETRAÇÃO }\end{array}$} & $\begin{array}{c}\text { FISSURAS DE DESTACAMENTO DE } \\
\text { PAREDES DE ALVENARIA POR RETRAÇÃO }\end{array}$ \\
\hline & & $\begin{array}{c}\text { FISSURAS VERTICAIS EM PAREDES POR } \\
\text { RETRAÇÃO DA ALVENARIA }\end{array}$ \\
\hline & $\begin{array}{l}\text { FISSURA INDUZIDA POR } \\
\text { SOBRECARGA } \\
\end{array}$ & $\begin{array}{c}\text { FISSURAS POR SOBRECARGAS EM TORNO } \\
\text { DE ABERTURAS }\end{array}$ \\
\hline IMPERMIABILIZAÇÃO & & UMIDADE GENERALIZADA \\
\hline \multirow{2}{*}{ PISOS } & & TRINCAS \\
\hline & & DETERIORAÇÃO DE JUNTAS \\
\hline FORRO DE GESSO & & TRINCAS E FISSURAS \\
\hline
\end{tabular}

\section{CONCLUSÕES}

Foram mostrados, ao longo do trabalho, defeitos que ocorrem no dia a dia e que, por muitas vezes, não são tratados com a solução adequada que necessitam por falta de conhecimento, por isso a importância de se trabalhar com profissionais capacitados, seja na hora do projeto, para detectar possíveis manifestações patológicas futuras, como as fissuras, ou durante a obra para evitar defeitos com causas na execução. 
Esse trabalho permitiu um maior conhecimento sobre o tema, manifestações patológicas: fatores que influenciam no aparecimento em casas residências, e quais os cuidados e tratamentos devem ser tomados com cada caso, o que traz a certeza da necessidade de lidar sempre com profissionais habilitados para tal e materiais condizentes com a qualidade que deve estar presente em toda e qualquer edificação.

\section{REFERÊNCIAS}

ASSOCIAÇÃO BRASILEIRA DE NORMAS TÉCNICAS. NBR 9575: Impermeabilização - Seleção e projeto, p. 14, 2010.

BARROS, M. M. S. B.; FLAIN, E. P.; SABBATINI, F. H. Tecnologia de Produção de Revestimentos de Piso. (Texto Técnico) - Escola Politécnica da USP. Departamento de Engenharia de Construção Civil, São Paulo, 1993.

BENTO, A. et al. A INFLUÊNCIA DA NBR 15575 (2013) NA DURABILIDADE E VIDA ÚTIL DAS EDIFICAÇÕES RESIDENCIAIS. In: Seminário de Patologia e Recuperação Estrutural (SEMIPAR), 2016, Recife. Anais [...]. Recife: UFPE, 2016.

FACHIN, K. A.; RIVELINE, A. R. B. MANIFESTAÇÕES PATOLÓGICAS: DECORRENTES EM EDIFICAÇÕES RELIGIOSAS. Revista UNINGÁ, Ingá, v. 28, p. 85-91, 2016.

FERREIRA, R. P. Como a crise afetou a construção civil. Jornal do Comércio, Porto Alegre, 22 jul. 2018. Disponível em: <https://www.jornaldocomercio.com/_conteudo/opiniao/2018/06/634231-como-a-crise-afetou-a-construcaocivil.html>. Acesso em: 25 out. 2019.

FRANÇA, Alessandra A. V.; MARCONDES, Carlos Gustavo N.; ROCHA, Francielle C. da; MEDEIROS, Marcelo Henrique Farias de; HELENE, Paulo R. L. Patologia das construções: uma especialidade na engenharia civil. Téchne, São Paulo, v. 19, n. 174, p. 72-77, 2011.

LIMA, B. S. Principais Manifestações Patológicas Em Edificações Residenciais Multifamiliares. 2015. Trabalho de conclusão de curso (Graduação em Engenharia Civil) - Centro de Tecnologia da Universidade Federal de Santa Maria, Santa Maria, 2015.

MAGALHÃES, E. F. FISSURAS EM ALVENARIAS: CONFIGURAÇÕES TÍPICAS E LEVANTAMENTO DE INCIDÊNCIAS NO ESTADO DO RIO GRANDE DO SUL. 2004. Trabalho de conclusão (Mestrado em Engenharia) - Universidade Federal do Rio Grande do Sul. Escola de Engenharia. Curso de Mestrado Profissionalizante em Engenharia. Porto Alegre, 2004.

MARCONI, M. A.; LAKATOS, E. M. Fundamentos de Metodologia Científica. 5. ed. SÃO PAULO: Atlas S.A, 2003.

MASSETTO, L. T.; SABBATINI, F. H. Estudo comparativo da resistência das alvenarias de vedação de blocos utilizadas na região de São Paulo. Anais.. São Paulo: Epusp/PCC, 1998.

RHOD, A. B. Manifestações patológicas em revestimentos cerâmicos: análise da frequência de ocorrência em áreas internas de edifícios em uso em Porto Alegre. 2011. Trabalho de Diplomação (Graduação em Engenharia Civil) Departamento de Engenharia Civil, Universidade Federal do Rio Grande do Sul, Porto Alegre, 2011.

SOUZA, M. F. PATOlogias OCASIONADAS PELA UMIDADE NAS EDIFICAÇÕES. 2008. Monografia (Especialista em Construção Civil) - Escola de Engenharia da UFMG, Belo Horizonte, 2008.

THOMAZ, E. TRINCAS EM EDIFÍCIOS - CAUSAS, PREVENÇÃO E RECUPERAÇÃO. SÃO PAULO: Pini, 1989.

VIEIRA, P. C. C. PATOLOGIAS EM INSTALAÇÕES HIDRO-SANITÁRIAS DE EDIFÍCIOS RESIDENCIAIS NA ZONA CENTRO-SUL DE MANAUS (AM): DIAGNÓSTICO E TERAPIA. 2016. Dissertação ( Pós-Graduação em Engenharia de Processos) - Universidade Federal do Pará, Belém, 2016. 